\title{
ESTUDO LONGITUDINAL DO PERFIL SOROLÓGICO PARA A CIRCOVIROSE EM GRANJAS DE SUÍNOS UTILIZANDO TESTES IMUNOENZIMÁTICOS (ELISA) AVALIAÇÃO SOROLOGICA PARA CIRCOVIROSE
}

\author{
MASSON, G. C. I. H. ${ }^{1}$ \\ CARVALHO, L. F. O. S. ${ }^{2}$ \\ OLIVEIRA, L.G. ${ }^{3}$ \\ IBRAHIM, N. A. F. I. ${ }^{4}$ \\ FERREIRA, G.S. ${ }^{5}$
}

\begin{abstract}
RESUMO: A circovirose é considerada uma doença emergente e responsabilizada por grandes prejuízos econômicos para a suinocultura. Estudos de prevalência e incidência no Brasil ainda são escassos principalmente utilizando o teste de ELISA. O objetivo deste trabalho foi realizar um estudo longitudinal determinando a presença de anticorpos anti - CVS - 2 em sete sistemas de produção de suínos do Estado de São Paulo avaliando o tipo e tempo de infecção e comparando os valores de densidade óptica com as lesões macro e microscópicas encontradas em 65 leitões necropsiados e após coloração por HE e imunoistoquimica. Os resultados sorológicos comprovaram a presença do vírus em todas as granjas e um percentual de $41 \%$ de animais soropositivos para CVS-2 sendo que 31,4\% dos animais apresentaram infecção com mais de dois meses, 7,9\% infecção recente entre um e dois meses e 1,7\% estavam com a infecção ativa. Todos os animais apresentaram diversas lesões frequentemente encontradas em animais doentes, entretanto, a identificação por imunoistoquimica não foi possível.
\end{abstract}

Palavras chaves: CVS - 2. Síndrome da refugagem multisistêmica. Soroperfil. IgG. IgM.

\section{USE OF IMMUNOABSORVENT ASSAY TEST (ELISA) TO DETERNINE THE LOGITUDINAL SEROPRIFILE OF CIRCOVIRUS INFECTION ON PIGS FARM}

SUMMARY: Porcine circovirosis is considered an emerging disease responsible for great economic losses to the swine industry. Prevalence and incidence studies in Brazil using ELISA test at the present are not related. The aim of this study was to determining the longitudinal presence of anti- PCV-2 in seven swine farms in São Paulo State and evaluating the type and duration of infection and comparing the optical density values with macro and microscopic lesions of 65 necropsied after HE staining and immunohistochemistry. The serological results confirmed the presence of the virus in all farms and a percentage of $41 \%$ of seropositive animals for PCV-2. 31,4\% pigs showed infection with more than two months, 7,9\% a recent infection between two months and $1,7 \%$ had active infection. All animals showed several lesions commonly found in sick animals however the immunohistochemistry identification was not possible.

Keywords: PCV2. Posweading wasting multisistemic syndrome. Seroprofile. IgG. IgM.

\footnotetext{
${ }^{1}$ Doutorando junto ao Departamento de Clínica e Cirurgia Veterinária, Universidade Estadual Paulista (Unesp) Campus de Jaboticabal - Agência Goiana de Defesa Agropecuária (AGRODEFESA), Praça Moisés Franco Qd L Lt 01 no 14 Centro - Cep 75.355-000, Varjão - GO, E-mail: guidomasson@ gmail.com

${ }^{2}$ Prof. Dr. do Departamento de Clínica e Cirurgia Veterinária, Universidade Estadual Paulista (Unesp) Campus de Jaboticabal

3 Gerente Estadual do Programa de Sanidade de Suídeos do Estado de São Paulo - Coordenadoria de Defesa Agropecuária do Estado de São Paulo

${ }^{4}$ Mestrando junto ao Departamento de Clínica e Cirurgia Veterinária, Universidade Estadual Paulista (Unesp) Campus de Jaboticabal

${ }^{5}$ Mestranda junto ao Departamento de Clínica e Cirurgia Veterinária, Universidade Estadual Paulista (Unesp) Campus de Jaboticabal
} 


\section{INTRODUÇÃO}

O circovirus suíno do tipo 2 (CVS-2) é um DNA vírus de fita simples, não envelopado com aproximadamente $1.7 \mathrm{~kb}$ pertencente a família Circoviridae no gênero Circovirus (LUKERT et al., 1995). Ele é o agente primário da circovirose suína (SEGALÉS et al., 2005) e sua presença é essencial para que ocorra a doença. Entretanto, sem a presença de co-fatores raramente o CVS-2 é capaz de causar a doença (OPRIESSING, et al., 2009). Assim sendo a circovirose é considerada uma doença multifatorial e sua manifestação e severidade é influenciada por fatores intrínsecos como o capacidade imunitária do animal e predisposição genética (OPRIESSING et al., 2006A, OPRIESSING et al., 2009) bem como extrínsecos, com destaque para as condições ambientais e de manejo.

O CVS-2 é um vírus ubiquo estando presente em muitas regiões onde a suinocultura é expressiva (ALLAN; ELLIS, 2000; SEGALÉS et al., 2004) podendo ser detectado em granjas com ausência ou presença das manifestações clínicas da circovirose, destacando-se a síndrome da refugagem multissistêmica (SRM), considerada, mundialmente por sua expressiva perda econômica em decorrência do aumento da mortalidade, diminuição do desempenho dos animais e altas taxas de refugagem (PINTO et al., 2011).

A doença acomete suínos entre 5 a 16 semanas de idade (HARDING; CLARK, 1997; ALLAN; ELLIS, 2000; SEGALÉS et al., 2004) e suas manifestações clínicas podem diferir entre granjas (OPRIESSING et al., 2006B) mas, geralmente são acompanhadas de perda progressiva de peso, dispnéia, aumento dos linfonodos, diarréia, palidez e icterícia. (ALLAN; ELLIS, 2000; SEGALÉS et al., 2004) além de problemas respiratórios (CLAK, 1997;

SEGALÉS et al., 2005), falhas reprodutivas e a síndrome dermatite e nefropatia (OPRIESSNIG et al., 2007). Infecções secundárias por outros agentes oportunistas também podem estar presentes, sugerindo uma imunossupressão (MANKERTZ; FINSTERBUSCH, 2009).

As lesões macroscópicas são variadas, entretanto a linfoadenopatia e a pneumonia intersticial são as mais frequentes. Lesões histológicas incluem infiltrados linfohistiocíticos e granulomatosos no pulmão, fígado, rim e depleção linfocitária nos tecidos linfóides (CLARK, 1997). Ocasionalmente, ainda observa-se a presença de corpúsculos de inclusão intracitoplasmáticos (SEGALÉS et al., 2005).

Vírus O CVS-2 é um vírus emergente que pode causar infecção persistente nos suínos (RODRÍGUEZ-ARRIOJA et al., 2002). Sua transmissão ocorre por meio do contato direto entre animais infectados e susceptíveis pelas vias oronasal, fecal e urinária (MAGAR et al., 2000) mas as secreções nasais ou as partículas em aerossóis são apontadas como a principal 
forma de transmissão horizontal (CAPRIOLI et al., 2006). A transmissão vertical também já foi comprovada (LADEKJAER et al., 2001; SAHA et al.; 2010) inclusive após a inseminação artificial com sêmen infectado (MADSON et al.; 2009).

Técnicas laboratoriais como a sorologia e detecção do DNA em soro de suínos representam uma importante ferramenta para determinação da presença do vírus em sistemas de produção de suínos podendo ser aplicadas em granjas com e sem a presença da SRM (GRAU-ROMA et al., 2009). Segundo Gerber et at. (2009) a maioria das granjas são soropositivas para CVS-2, mas nem todas apresentam surtos ou casos isolados de SRM e o perfil sorológico pode variar entre rebanhos de acordo com a idade, fase de produção e manifestações de sinais clínicos.

Rebanhos europeus apresentaram índices de positividade próximos a 100\% (LAROCHELLE et al., 2003). Dados sorológicos em rebanhos Brasileiros demonstram elevada prevalência. Em 2008, Barbosa et al. realizaram um estudo em Minas Gerais, Santa Catarina e no Rio Grande do Sul descrevendo por meio da Imunoperoxidase em monocamada de células uma prevalência de 95,4\%. No Mato Grosso, 58,21\% das amostras de linfonodos e tonsilas submetidas à PCR foram positivas (OLIVEIRA FILHO et al., 2009) e recentemente um trabalho descrevendo a dinâmica da circulação viral ao longo da cadeia produtiva também sugeriu uma elevada prevalência do vírus em granjas com e sem SRM (PINTO et al., 2011).

Os resultados descritos pela literatura foram tomados como ponto de partida para a realização do presente estudo. Os objetivos foram determinar a prevalência sorológica por meio de ensaios imunoensimáticos (ELISA) em sete granjas de suínos no Estado de São Paulo e comparar os resultados sorológicos às lesões histológicas e a aos resultados de imunoistoquímica (IHC).

\section{MATERIAL E MÉTODO}

\section{Granjas}

Foram visitadas sete granjas de suínos de ciclo completo (G1, G2, G3, G4, G5, G6 e G7). Durante a visita realizou-se uma avaliação do grau de vulnerabilidade das granjas para doenças conforme sua classificação em níveis de biossegurança de acordo com IN 19 de 2002 do MAPA (BRASIL, 2002.). Realizou-se a coleta de dados zootécnicos, produtivos e sanitários seguindo-se de um exame clínico do rebanho.

Foram colhidas 478 amostras de sangue de todas as categorias animais - porcas lactantes (PM), leitões lactentes (LM), leitões de creche (LC), suínos em crescimento (C), suínos em terminação (T), porcas gestantes (PG) e animais em quarentena (Tabela 1). Todas as amostras de sangue foram dessoradas por centrifugação no Laboratório de Pesquisa em 
16

Clínica e Cirurgia Veterinária do Departamento de Clínica e Cirurgia da FCAV- Unesp

Campus de Jaboticabal e imediatamente congeladas a $-20^{\circ} \mathrm{C}$ até o momento da análise.

Ao término do período de coleta, as amostras de soro foram submetidas ao teste de ELISA de captura $^{6}$ conforme orientações do fabricante. A leitura foi realizada em comprimento de onda $450 \mathrm{~mm}$ e o ponto de corte de cada placa foi determinado pela densidade óptica referente aos controles positivos de cada isômero IgG ou IgM multiplicandose o valor de leitura encontrado em cada placa por 0,4 e 0,3 respectivamente. Os controles negativos foram aplicados apenas com a função de proporcionar segurança ao teste.

\section{Necropsia}

Selecionou-se para necropsia 65 animais em fase de creche e crescimento, com histórico de perda de peso e emagrecimento, mucosas hipocoradas, carcaça magra, cerdas visivelmente evidentes e linfoadenopatia regional. Os animais foram sacrificados após exame clínico, conforme aprovação prévia do Conselho de Ética e Bem-Estar Animal. Durante a necropsia realizou-se avaliação macroscópica de órgãos internos bem como coleta de pulmão, coração, fígado, baço, linfonodos (mandibulares, mediastínicos, mesentéricos e inguinais), rim, encéfalo e cerebelo. Todos os tecidos coletados foram processados para análises histopatológicas e coradas pelo método de Eosina Hematoxilina (HE) convencionais. Os cortes de linfonodos foram também preparados para imunoistoquímica conforme (SOUZA et al., 2008)

\section{RESULTADOS}

Na tabela 1 estão representados dados zootécnicos das granjas amostradas, dados de doenças respiratórias bem como o grau de vulnerabilidade das granjas calculado conforme a Instrução Normativa n ${ }^{\circ} 19$ de 2002 do Ministério da Agricultura Pecuária e Abastecimento do Brasil.

\footnotetext{
${ }^{6}$ Ingezim Circovirus IgG/IgM (Prod. Ref.: 11. PCV.K2), Ingenasa, Madri, ESpanha
}

Nucleus Animalium, v.3, n.2, nov. 2011 
Tabela 1: Características gerais das granjas de suínos amostradas para o estudo da ocorrência do circovirus suínos, Jaboticabal, 2011.

\begin{tabular}{llllllll}
\hline Características & G1 & G2 & G3 & G4 & G5 & G6 & G7 \\
\hline Número de Matrizes & 450 & 500 & 200 & 300 & 500 & 45 & 400 \\
Taxa de mortalidade & $\mathrm{N}$ & $\mathrm{N}$ & $\mathrm{N}$ & $\mathrm{N}$ & $\mathrm{NI}$ & $\mathrm{N}$ & $\mathrm{N}$ \\
Doença respiratória & $\mathrm{TCT}$ & $\mathrm{SE}$ & $\mathrm{Co}$ & $\mathrm{Co}$ & Alta $*$ & $\mathrm{ND}$ & $\mathrm{SE}$ \\
Manejo das instalações & $\mathrm{MC}$ & $\mathrm{AO}$ & $\mathrm{AO}$ & $\mathrm{AO}$ & $\mathrm{MC}$ & $\mathrm{MC}$ & $\mathrm{AO}$ \\
Biosseguridade & $\mathrm{B}$ & $\mathrm{A}$ & $\mathrm{B}$ & $\mathrm{A}$ & $\mathrm{D}$ & $\mathrm{A}$ & $\mathrm{C}$
\end{tabular}

G1 a G7 = granjas 1 a 7, N = valores aceitáveis entre 2 a $5 \%$ e estimados, $\mathrm{NI}=$ não informado, $\mathrm{TCT}=$ tosse no crescimento e terminação após movimentação dos animais, $\mathrm{SE}=$ Surtos esporádicos, $\mathrm{Co}=$ controlada, $\mathrm{ND}=$ não determinado, $\mathrm{MC}=$ Manejo contínuo, $\mathrm{AO}=$ All-in all-out, $\mathrm{A}=$ granja bem protegida, $\mathrm{B}=$ vulnerabilidade baixa, $\mathrm{C}=$ vulnerabilidade média, $\mathrm{D}=$ altamente vulnerável.

O circovírus mostrou-se um agente importante nas granjas avaliadas uma vez que todas foram positivas. Dentre as 478 amostras de soro, 196 (41\%) foram positivas comprovando que o CVS-2 esta presente e circulando nas granjas de suínos (Tabela 1). A avaliação das densidades ópticas para $\operatorname{IgM}$ e $\operatorname{IgG}$, permitiu a classificação do tipo de infecção bem como o tempo decorrido em meses. O perfil da resposta que classificou o tipo e o tempo decorrido a partir da infecção como animal que não soro converteu, infecção com mais de dois meses, infecção ativa ou infecção entre um e dois meses foi possível após análises dos valores de densidade óptica encontrados para $\operatorname{IgG}$ e $\operatorname{IgM}$ frente ao vírus e estão representados graficamente na Figura 1.

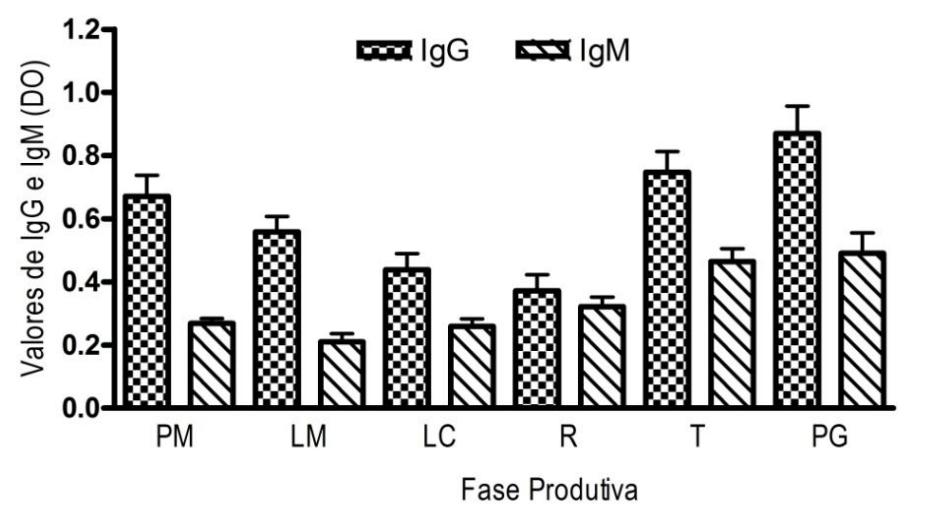

Figura 1: Representação gráfica dos valores de DO encontrados para IgG e $\operatorname{IgM}$ em soro sanguíneo de suínos após contato ou infecção pelo CVS-2, conforme fases produtivas, (PM porca lactante, LM - leitão lactente, LC - leitão em fase de creche, R suíno em crescimento, T - suíno em fase de terminação, PG - Porcas gestantes) em granjas da região de Jaboticabal, SP.

Ao todo, 31,4\% dos animais apresentaram infecção com mais de dois meses. As infecções classificadas como infecção ativa e recente (entre 1 e 2 meses) foram respectivamente $1,7 \%$ e 7,9\%. A Figura 2 representa graficamente a distribuição de anticorpos 
contra CVS-2 em amostras de soro coletados de suínos de diferentes fases de produção entre as granjas amostradas neste estudo.

Animal saudável $\square$ Infecção Ativa $\square$ Infecção Recente $\square$ Infecçăo com mais de 2 meses

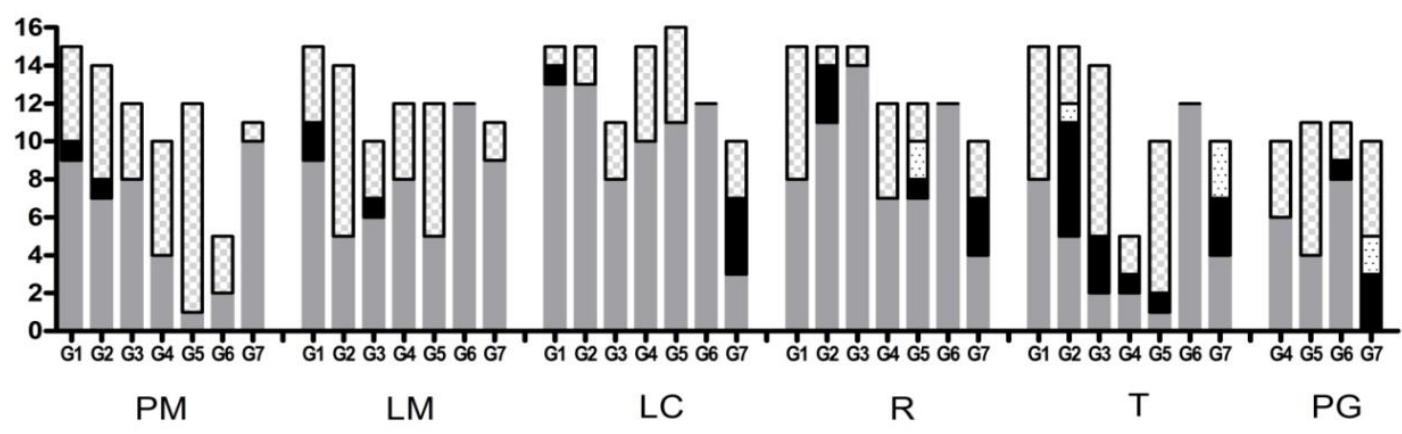

$\mathrm{PM}=$ Porca Maternidade; LM=Leitão Maternidade; LC=Leitão Creche; R=Recria; PG=Porca Gestação

Figura 2: Perfil sorológico longitudinal, tempo de infecção determinado pelo método de ELISA de captura da Ingenasa (Madri, Espanha) - Ingezim Circovírus IgG/IgM (Prod Ref: 11.PCV.K2.) em granjas de suínos na região de Jaboticabal, SP.

As avaliações sorológicas dos animais necropsiados revelaram que $25 \%$ dos animais soroconverteram da seguinte forma: três leitões estavam com infecção ativa, dois apresentaram resposta característica de infecção recente, entre 1 e 2 meses e 11 leitões com infecção com mais de 2 meses. Nestes animais, macroscopicamente, visibilizou-se lesões intestinais, principalmente no íleo, estômago com variado grau de úlceras e linfoadenopatia regional nos linfonodos - ileo-cólicos e mesentéricos. Muitos animais apresentaram ainda acumulo de líquido (ascite) na cavidade abdominal. Lesões pulmonares variando em vários graus e tipos inclusive abscessos também estavam presentes. As lesões microscópicas encontradas com maior frequências estão sumarizadas na tabela 2. Não foram encontrados antígenos para CVS-2 em linfonodos submetidos à IHC.

\section{DISCUSSÃO}

Todas as granjas envolvidas neste estudo demonstraram a presença do CVS-2 e a circulação longitudinal demonstrada pelos animais que soroconverteram em algum momento do ciclo de produção. Estes achados estão em acordo com aqueles descritos em outros estudos (ALLAN; ELLIS, 2000; MAGAR et al., 2000; LAROCHELLE et al., 2003; OPRIESSNIG et al., 2004; GERBER et at., 2009; OLIVEIRA FILHO et al., 2009; PINTO et al., 2011).

A SRM muitas vezes pode não ser descrita em rebanhos por causa de sua forma subclínica favorecida pela ausência de co-fatores que exacerbariam a manifestação clínica da doença. Todas as granjas visitadas indicaram a existência e a circulação viral e apesar da elevada $(41 \%)$ soroprevalência encontrada nos animais, em sua grande maioria infecções com 
mais de dois meses $(31,4 \%)$ e uma pequena percentagem $(1,7 \%)$ de animais com infecção ativa não foram observadas, manifestações clínicas associados à circovirose salvo alguns casos individuais como os suínos necropsiados.

Curiosamente não foram observados pela IHC em linfonodos antígenos para CVS-2. O período ideal de detecção para antígenos pela técnica de IHC encontra-se entre sete a dez dias e após este período a sensibilidade do teste sofre um decréscimo, prevalecendo lesões microscópicas, que são sugestivas para doença (OPRIESSING et al., 2009). A infecção ativa determinada pela presença de $\operatorname{IgM}$ aumenta a possibilidade de detecção antígenos, entretanto o período de médio para soroconversão é de 14 dias com declínio entre 21 a 28 dias (OPRIESSING et al., 2006B). Acreditamos que o tempo decorrido entre infecção e a viremia no momento da necropsia tenha sido superior a dez dias e por isto não foi possível a visualização nas amostras avaliadas.

A patogenia e o grau das lesões podem ser atribuídos ao fator virulência determinada por pequenas diferenças no genoma do vírus (OPRIESSING et al., 2006B) ou ainda pela genética do animal. Diferenças e severidade em lesões ocasionadas pelo CVS-2 são descritas entre raças de suínos. Animais da raça Landrace são mais susceptíveis as lesões quando comparados as raças Large White e Duroc (OPRIESSING et al., 2006A) e Pietrain (OPRIESSING et al., 2009). Consequentemente, esta susceptibilidade também é observada nos cruzamentos entre raças (LOPEZ-SORIA et al., 2004).

A imunidade passiva, geralmente confere proteção contra infecções virais em leitões recém-nascidos. Os níveis de Anticorpos maternos são muito importantes na determinação da resposta imunológica dos leitões, de maneira que quanto maior a transferência de anticorpos maior será a proteção do leitão (MCKEOWN et al., 2005). A capacidade do CVS -2 em cruzar a barreira transplacentária após a inoculação intranasal e oronasal durante a gestação e causar a infecção fetal foi comprovada pela detecção de anticorpos anti CVS-2 e a presença de DNA viral em amostras soro de leitões colhidas antes da ingestão de colostro (MADSON et al., 2009). O mesmo estudo demonstrou que fetos imunocompetentes (> 70 dias de gestação) são capazes de limpar a infecção antes do parto e não apresentarem lesões ou anticorpos para CVS-2. Ainda em relação ao grau e severidade de lesões, outros estudos demonstram que a imunoestimulação promovida pelo uso de vacinas com adjuvantes (ALLAN et al., 2000b; OPRIESSNIG et al., 2003 ) podem aumentar a gravidade das manifestações clínicas e das lesões. Neste estudo todas as granjas não vacinavam porcas e ou leitões para a circovirose.

Como descritos pela literatura muitos são os aspectos e fatores que podem interferir na manifestação clínica e na severidade das lesões provocadas pelo CVS-2. No Brasil há uma escassez na literatura e ainda há muito a pesquisar sobre diferenças genotípicas entre as 
amostras de CVS-2 isoladas de suínos a campo e suas correlações com aspectos clínicos, patológicos e epidemiológicos.

\section{CONCLUSÃO}

Este estudo demonstrou a ampla distribuição e a circulação do CVS-2 nas fases do ciclo de produção e em diferentes granjas comerciais de suínos. A eficácia do teste de ELISA para a detecção de anticorpos anti -CVS-2 foi comprovada mostrando-se como uma excelente opção para o controle e o diagnóstico da circovirose suína em granjas onde a SRM esta presente ou ausente.

\section{AGRADECIMENTOS}

A FAPESP pelo apoio financeiro (Processo 2006/57775-0), sem o qual não seria possível a realização deste trabalho.

\section{REFERÊNCIAS}

ALLAN, G.M.; ELLIS, J.A. Porcine circoviruses: a review. Journal of Veterinary Diagnostic and Investigation, n.12, p. 3-14. 2000.

ALLAN, G. M.; MCNEILLY, F.; KENNEDY, S.; MEEHAN, B.; ELLIS, J.; KRAKOWKA, S. Immunostimulation, PCV-2 and PMWS. Veterinary Record, n.147, p. 170-171. 2000b.

BARBOSA, C.N.; LOBATO, Z.I.P.; MARTINS, N.R.S.; NASCIMENTO, E. F. Perfil sorológico para circovírus suíno tipo 2 em granjas comerciais de suínos no Brasil. Arquivo Brasileiro de Medicina Veteterinária e Zootecnia, v.60, n.4, p.815-820. 2008.

BRASIL, Instrução Normativa ${ }^{\circ}$ 19, de 15 de fevereiro de 2002, Estabelece normas a serem cumpridas para a Certificação de Granjas de Reprodutores Suídeos, Ministério da Agricultura Pecuária e Abastecimento (MAPA). Secretaria de Defesa Agropecuária.

CAPRIOLI A. et al. PCR detection of porcine circovirus type 2 (PCV2) DNA in blood, tonsillar and faecal suabes from experimentally infected pigs. Research in Veterinary Science. n.81, p.287-292. 2006.

CLARK, E. Postweaning Multisystemic Wasting Syndrome. American Association of Swine Practitioners, p.499-501. 1997.

GERBER, P. et al. Distribution of antibodies against porcine circovirus type-2 (PCV2) in single site and multi-site farrow-to-finish farms in Brazil. Research in Veterinary Science. n.87, p.488-491. 2009.

GRAU-ROMA, L.et al. Infection, excretion and seroconversion dynamics of porcine circovirus type 2 (PCV2) in pigs from post-weaning multisystemic wasting syndrome (PMWS) affected in Spain and Denmark. Veterinary Microbiology. n.135, p.272 - 282. 2009. 
HARDING, J. C.; CLARK, E. G. Recognizing and diagnosing postweaning multisystemic wasting syndrome (PMWS). Journal of Swine Health Production. n.5, p.201-203. 1997.

LADEKJAER-MIKKELSEN, A.S. et al. Transplacental infection with PCV-2 associated with reproductive failure in a gilt. Veterinary Record. n.148, p.759-760, 2001.

LAROCHELLE, R.; MAGAR, R.; D’ALLAIRE, S. Comparative serologic and virologic study of commercial swine herds with and without postweaning multisystemic wasting syndrome. Canadian Journal of Veterinary Research. n.67, p.114-120. 2003.

LOPEZ-SORIA, S.et al. Genetic influence on the expression of PCV disease. Veterinary Record. n.155, p.504. 2004.

LUKERT, P.et al. Virus taxonomy sixth report of the International Committee on Taxonomy of viruses. In: MURPHY, F. A.et al. Summers (ed.), Springer-Verlag, Vienna, Austria. The Circoviridae. p. 166-168. 1995

MADSON, D. M.et al. Effect of porcine Circovirus Type 2 (PCV2) Vaccination of Dam on PCV2 Replication In Utero. Clinical and Vaccine Immunology. v.16, n. 6, p.830-834. 2009.

MAGAR, R. et al. Experimental transmission of porcine circovirus type 2 (PCV2) in weaned pigs: A sequential study. Journal of Comparative Pathology. n.123, p.258-269. 2000.

MANKERTZ, A.; FINSTERBUSCH, T. Porcine circoviruses - Small but powerful. Virus Research. n.143, p.177 - 183. 2009.

MCKEOWN, N.E. et al. Porcine Circovirus Type 2 (PCV2) Maternal Antibodies on Experimental Infecction of Piglets with PCV2. Clinical and Diagnostic Laboratory Immunology. v.12, n. 11, p.1347-1351. 2005.

OLIVEIRA FILHO, J. X. et al. Ocorrência de circovirus suíno tipo 2 em suínos abatidos no estado do mata grosso Acta Scientifica Veterinária. n.37, v.4, p. 363-366. 2009.

OPRIESSNIG, T. et al. Effect of vaccination with selective bacterins on conventional pigs infected with type 2 porcine circovirus. Veterinary Pathology. n.40, p.521-529. 2003.

OPRIESSNIG, T.et al. Derivation of porcine circovirus type 2-negative pigs from positive breeding herds. Journal Swine Health Production. n.12, p.186-191. 2004.

OPRIESSNIG, T.et al. Evidence of breed-dependent differences in susceptibility to porcine circovirus type-2-associated disease and lesions. Veterinary Pathology. n.43, p.281-293. 2006A.

OPRIESSING, T.et al. Genetic and experimental comparision of porcine circovirus type 2 (PCV2) isolates from cases with and without PCV2- associated lesions provides evidence for differences in virulence. Journal of General Virology. n.87, p.2923 - 2932. 2006B.

OPRIESSNIG, T.; MENG, X.-J.; HALBUR, P.G. Porcine Circovirus Type 2 associated disease: update on current terminology, clinical manifestations, pathogenesis, diagnosis, and 
intervention strategies. Journal of Veterinary Diagnostic Investigation. n.19, p.591-615. 2007.

OPRIESSNIG, T.et al. Difference in severity of porcine circovirus type two-induced pathological lesions between Landrace and Pietrain pigs. Journal of Animal Science. n.87, p.1582- 1590. 2009.

PINTO, F.F.et al. Perfil sorológico, viremia e eliminação do circovírus suíno tipo $2 \mathrm{em}$ animais naturalmente infectados pertencentes a granjas com ou sem a síndrome da refugagem multissistêmica. Pesquisa Veterinária Brasileira. v.31, n. 1, p.17-22. 2011.

RODRÍGUEZ-ARRIOJA, G. M.et al. Dynamics of porcine circovirus type 2 infection in a herd of pigs with postweaning multisystemic wasting syndrome. American Journal of Veterinary Research. n.63, p.354-357. 2002.

SAHA, D.et al. Pon porcine foetuses after experimental inoculation with Pathologic and virologic findings in mid-gestation porcine foetuses after experimental inoculation with PCV2a or PCV2b. Veterinary Microbiology. n.145, p.62-68. 2010.

SEGALÉS, J.; ROSELL, C.; DOMINGO, M. Pathological findings associated with naturally acquired porcine circovirus type 2 associated disease. Veterinary Microbiology. n.98, p.137149. 2004.

SEGALÉS, J.; ALLAN, G.M.; DOMINGO, M. Porcine circovirus diseases. Animal Health Research Reviews. n.6, p.119-142. 2005.

SOUZA, N. N.; LOBATO, Z.I.P.; GUDES, R.M.C. Estudo retrospectivo de diagnóstico de circovirose suína pela técnica de imunoistoquímica. Arquivos do Instituto Biológico v.75, n.4, p.521 - 525. 2008. 